\title{
TRES MATRICES \\ DEL LENGUAJE-PENSAMIENTO
}

\section{Lúcia Santaella}

Desde hace muchos años, la lectura, descripción y análisis de los más diversos tipos de discursos verbales y procesos sígnicos no verbales han estado en el centro de mis preocupaciones.

El metabolismo de los sistemas de lenguaje se asemeja al de los seres vivos. Como los organismos vivos, los lenguajes están en permanente crecimiento y mutación. Los procesos de parentesco, trueque, migración e intercambio entre los lenguajes no son menos densos y complejos que los que rigen la demografía humana. En fin, el mundo de los lenguajes parece ser tan móvil y volátil como el mundo de los vivos. A pesar de eso, no abdiqué de la búsqueda de inteligibilidad de posibles leyes generales que están por debajo de todos los fenómenos sígnicos.

Pero para tal búsqueda, el primer paso será el de no dividir los lenguajes en campos herméticos, rígidamente cerrados: la literatura y las formas narrativas en un compartimento, la pintura en otro, el cine de un lado, la fotografía de otro, el vídeo aquí y la música allá... Contrariamente, a la vez que el tiempo pasa, me convenzo más de que 
es sólo en los curricula escolares donde los lenguajes están separados con nitidez. En la vida existe la promiscuidad, «la mezcla es el espíritu» de los signos.

En síntesis, en la base de mi propuesta está la convicción de que hay raíces lógicas que determinan la constitución de todo y cualquier sistema de signos. Esas raíces son mucho más profundas que lo que la superficie de los mensajes y de los canales que las promueve nos puede llevar a percibir. Sin negar la multiplicidad, además, que sólo tiende histórica y antropológicamente a crecer cada vez más, postulo que debajo de esa multiplicación manifiesta hay sólo tres y tan sólo tres matrices lógicas, a partir de los cuales, por procesos de combinación y mezcla, se originan todas las formas posibles de lenguaje.

Esclareciendo mejor: los lenguajes, evidentemente, son muchos. Desde la Revolución Industrial y, más recientemente, la Revolución Electrónica e Informática, el poder multiplicador y el efecto proliferador de los lenguajes parece que se están ampliando enormemente. La era de las imágenes de registro físico de fragmentos del mundo, iniciada con la fotografía y seguida por el cine, TV, vídeo y holografía, por ejemplo, tiene tan sólo un siglo y medio de existencia y ya estamos instalados ahora en plena efervescencia de una era pos-fotográfica de génesis sintética de las imágenes y de una realidad virtual. Si, en el siglo pasado, la naturaleza - antigua fuente de inspiración de los pintores paisajistas - se había tornado tarjeta postal, hoy ella puede ser engendrada a través de números en los programas de los computadores. No hay casi nada de naturaleza real, artificial, simulada o ficticia que el imaginario numérico no pueda colocar en las pantallas de los monitores (recordemos que un tipo de descripción histórica similar es oportuna también para la música).

Además de crecer en la medida exacta en cada nuevo vehículo o medio inventado, los lenguajes también crecen a través del ajuste entre medios. El diario, por ejemplo, es, entre otras cosas, una unión feliz, entre el telégrafo (hoy transmutado en fax), la fotografía y la modificación cualitativa del lenguaje escrito en el espacio gráfico. El vídeotexto nació de la combinación de un banco de dados con el teléfono y un terminal de vídeo. En fin, el universo de los media nos ofrece una riqueza de ejemplos de hibridación de medios, códigos y lenguajes que no especificaremos aquí.

Recordaremos que esos procesos de hibridación actúan como propulsores en el crecimiento de los lenguajes. Es por ello por lo 
que los lenguajes invadieron literalmente el mundo. Estemos o no atentos a eso, estamos día y noche, noche y día, en cualquier rincón del planeta, con mayor o menor intensidad, totalmente inundados de signos y lenguajes. Y no hay indicio de que los lenguajes deberán parar de crecer. Por el contrario, estando superpoblado el planeta, la tendencia es que busquen nuevos hábitats en el espacio celeste.

Urge relativiza, por tanto, las visiones atomizadas de los lenguajes, códigos y canales, basados apenas en los modos de aparición de los mensajes, para que busquemos un tratamiento más económico e integrado que nos permita comprender cómo los signos se forman y cómo los lenguajes y los medios se combinan y se mezclan. Aunque la evidencia histórica de la necesidad de esa búsqueda sea fuerte, no fue a través de la mera observación crítica de la proliferación de los signos y lenguajes lo que me ha hecho llegar a las propuestas que aquí expongo. Éstas brotaron específicamente a partir de un germen teórico.Y en ellas persisto porque la teoría parece estar recibiendo el respaldo del Real. La teoría debe ser capaz de responder a un buen número de desafíos que la realidad muestra.

Propongo, entonces, que la variedad y multiplicidad crecientes de todas las formas de lenguaje están apoyadas en tres y no más que tres matrices de lenguaje-pensamiento: la matriz verbal, la matriz visual y la matriz virtual (que encuentra su forma ejemplar de expresión en la música). Todos los lenguajes, pese a la variedad de los canales y las diferencias específicas que adquieren en esos canales, tienen sus bases en esas matrices; más comúnmente en las combinaciones entre las varias modalidades en que cada una de esas matrices se subdivide.

La fuente teórica que inspiró esa propuesta está en la fenomenología y doctrina de signos del lógico, científico y filósofo norteamericano Charles Sanders Peirce (1839-1914). Para Peirce, la fenomenología tiene por función responder a la más antigua pregunta que la filosofía, desde sus principios, se ha hecho. ¿Cómo se da la aprehensión y comprensión del mundo por el hombre? ¿Cómo la multiplicidad y diversidad infinitas del universo sensible son convertidas en realidades inteligibles? Después de décadas del más apurado esfuerzo intelectual, Peirce concluyó que todo lo que nuestra mente es capaz de aprehender, todo lo que aparece a la conciencia, lo hace en una graduación de tres elementos: 1) calidad o sentimiento, 2) reacción y 3) mediación. Sus conclusiones van todavía más allá. Esos modos de aprehensión no son, 
para él, apenas elementos presentes en el acto de aprehender los fenómenos, $y$, por tanto, factores debidos a la naturaleza peculiar de nuestra mente, pero son también elementos formales integrantes de todo y cualquier fenómeno, sea físico, real, imaginado, soñado, recordado de la vivencia; en fin, todo y cualquier fenómeno, desde una niebla en el horizonte hasta un teorema matemático. En síntesis, esos elementos formales, que Peirce llama categorías, son los ingredientes más generales, abstractos y universales, de todo el universo. Siendo tan universales, por estar presentes en todo y cualquier cosa, Peirce resolvió variar los términos de cualquier contenido material, reduciéndolos a su naturaleza puramente lógica. En consecuencia, las categorías pasaron a ser designadas por 1) primeridad, 2) segundidad y 3) terceridad. En cada fenómeno particular, el ropaje aparente de esas categorías se modifica. No obstante el cambio de ropaje, el sustrato lógico siempre permanece. Si tomamos el caso del cosmos físico como ejemplo, las categorías aparecerán bajo la forma de 1) acaso, 2) leyes mecánicas y 3) tendencia del universo a adquirir nuevos hábitos.

Toda la obra de Peirce está fundada en esas categorías (Santaella, 1992). Su doctrina de los signos o semiótica está basada en las categorías y no se pueden comprender las sutilezas de sus innumerables clasificaciones de signos, sin un conocimiento cuidadoso de la fenomenología (Santaella, 1995). Guardando las debidas proporciones; pienso que también no se pueden aprehender mis tentativas de explicitación de las tres matrices de lenguaje, sin el presupuesto de una cierta intimidad con la obra de Peirce.

No es difícil inferir que mi postulación de las tres matrices (verbal, visual y virtual) está basada en las categorías. De ese modo lo virtual estaría en la primeridad, así como lo visual estaría en la segundidad y lo verbal en la terceridad. No son apenas las categorías que me suministraron datos para esa analogía, sino también todas las clasificaciones de signos correlativas a ellas. Lo que define básicamente la naturaleza del discurso verbal es verdaderamente el reino de la abstracción. Pues bien, esto corresponde con exactitud a las características de aquello que Peirce define como signo simbólico, el universo de la mediación y de las leyes. La característica primordial del lenguaje visual está en la insistencia con que las imágenes singulares, aquí y ahora, se presentan a la percepción. Ver es confrontar algo, aunque ese algo sea una imagen mental u onírica. Aliada a su carácter perceptivo, que corresponde típicamente al universo de la segundidad, el lenguaje visual tiene una vocación referencial, lo que lo categoriza como signo básicamente 
indicial. Esa vocación mimética de las imágenes transciende las determinaciones puramente históricas. Desde las primeras inscripciones en las grutas, el hombre siempre fue guiado por el deseo complejo y aparentemente eterno de duplicar el mundo. $Y$ el lenguaje virtual, que encuentra en la música su más perfecta forma de expresión, tiene un poder referencial fragilísimo, aliado a un alto poder de sugestión, lo que fundamentalmente lo coloca en el universo icónico de las más puras asociaciones por semejanza.

Cada uno de esos tipos de lenguaje tiene su eje de dominio en una de las categorías, de lo que resulta que lo verbal es fundamentalmente una cuestión del símbolo, lo visual una cuestión del índice y lo musical una cuestión del icono. Eso no quiere decir, entre tanto, que cada uno de esos lenguajes no pueda distanciarse de su eje de categorización. No hay nada más móvil, maleable y mutable que los lenguajes. Sin ello, además, ninguna creación sería posible. Dislocándose de su eje, un lenguaje comienza a adquirir características que son básicamente de otro lenguaje. Con esta base, lancé la hipótesis de que debería haber una redistribución de las tres categorías en el lenguaje anterior. Así, lo verbal, por ejemplo, que se define en la matriz del símbolo, se redistribuye también dentro de los caracteres de iconicidad y simbolicidad; como lo musical también se presenta con características indiciales y simbólicas.

Basándome en esa hipótesis, estructuré una clasificación del discurso verbal (cf. Santaella Braga, 1980 y 1990), que encontró respaldo en la tradicionalísima división de los discursos: descripción, narración y disertación. Así, la descripción está para la primeridad, tanto como la narración para la segundidad y la disertación para la terceridad. Una penetración en el interior de esa nueva tríada me llevó a percibir una repetida posibilidad de recursividad, o sea, percibí que, dentro de la descripción cabrían tres niveles, correspondiendo nuevamente a los caracteres de lo primero, segundo y tercero (descripción cualitativa, indicial y conceptual), ocurriendo lo mismo con la narrativa (espacial, sucesiva y causal) y la disertación (conjetural, relacional y argumentativa). Con eso llegué a nueve tipos de discursos posibles.

Después de algunos años de experiencia de aplicación práctica al estudio del discurso (ver Santaella, 1995 y Machado et al., 1984), comencé a realizar un trabajo semejante en relación con lo visual, sin desobedecer ciertamente las debidas especificidades de cada sistema de signos. El resultado de ese trabajo (Santaella, 1988, 1989) me 
hizo llegar a una clasificación de lo visual en: 1) formas representativas (primeridad, icono), 2) formas figurativas (segundidad, índice) y 3 ) formas representativas (terceridad, símbolo). Dentro de cada uno de esos tipos hay nuevamente una redistribución de las tríadas (1.1 cualidad reducida a sí misma, 1.2 cualidad como acontecimiento singular y 1.3 cualidad como ley; 2.1 la figura como cualidad, 2.2 la figura como registro y 2.3 la figura como convención; 3.1 representación por analogía, 3.2 representación por figuración y 3.3 representación por convención). Esos nueve tipos de lenguaje visual pueden ser capaces de funcionar como brújulas de orientación para la lectura de toda y cualquier imagen fija de cualquier naturaleza, bi o tri-dimensional.

La clasificación del lenguaje musical fue lo que más tiempo me llevó para su ejecución. Ello no era casual. Por estar en la matriz del icono, la música es la forma más abierta del lenguaje, desafiando cualquiera sistema de clasificación. Además de eso, no estaba en las intenciones de mi propuesta de clasificación tener por objeto estrictamente la producción musical de un cierto periodo de la historia, sino, al contrario, mi propuesta pretendía ser lógica y con poder de generalización con el fin de habilitar su aplicación a cualquier composición musical de cualquier especie. En fin, su universalidad y generalidad tiene que ser equivalente a las presentadas por la clasificación del discurso y por la clasificación de las formas en el lenguaje visual.

Teniendo en cuenta eso, el camino para la clasificación del lenguaje musical me llevó, entonces, a encontrar en la sintaxis el eje estructurador de la música (ver Koellreutter, 1988-1990). La perfección con que la sintaxis se presenta como atributo propio de la iconicidad, matriz semiótica de la música, tiende a aumentar cuando, a la luz de las categorías peirceanas, se compara la sintaxis con los ejes que caracterizan el lenguaje visual, de un lado, y el discurso verbal, de otro. $O$ sea, la sintaxis está para la música (primeridad), así como las figuras están para la visualidad (segundidad) y los discursos están para lo verbal (terceridad).

Considerando esto, la clasificación del lenguaje musical, a partir del eje de la sintaxis y de acuerdo con la recursividad de las tres categorías dentro de ese eje, aparece así: 1) sintaxis aleatoria, 2) sintaxis por coordinación o parataxis y 3) sintaxis por subordinación o hipotaxis. Entonces, reaplicando las tres categorías dentro de cada una de esas divisiones, según la misma lógica de recursividad que aplicamos en la clasificación de lo verbal y de lo visual, tendremos que la sintaxis alea- 
toria presentará las tres subdivisiones siguientes: 1.1 el juego del acaso, 1.2 improvisación y 1.3 la probabilidad. La sintaxis por coordinación o parataxis presentará sus subdivisiones de acuerdo con: 2.1multidimensionalidad o sucesividad, 2.2 monodimensionalidad $\mathrm{o}$ sucesividad y 2.3 cronometría. La sintaxis por subordinación presentará la subdivisión siguiente: 3.1 jerarquías icónicas, 3.2 jerarquías relacionales y 3.3 jerarquías convencionales.

Sintetizando, la sintaxis está para la música, así como la referencialidad está para lo visual y la representación para lo verbal, lo que compone elegantemente los tres grandes ejes de las tres matrices del lenguaje-pensamiento. Estando las tres matrices ya completamente clasificadas, eso sirve de base para la elaboración de los tipos de mezclas que pueden ocurrir entre esos veintisiete modos de estructuración de lenguaje, lo que nos da medios para establecer características de los sistemas sígnicos híbridos, tales como lenguaje verbal oral (que tiene fuertes trazos de hibridación con el lenguaje de la música), arquitectura (que, en sus aspectos rítmicos y harmónicos, también se entrelaza con la música), así como todas las formas de lenguaje visual en movimiento (cine, TV, vídeo y computación) que se cruzan tanto con modalidades de organización del lenguaje musical, como con las diversas modalidades de discurso verbal (narrativa, principalmente, debido a su vector temporal).

Debo notar que el surgimiento de los multimedia y supermedia, en sus mezclas de lo verbal, visual y sonoro, me ha servido como un gran estímulo para la continuidad de mis investigaciones sobre las tres matrices, sus diferentes modalidades y sus posibles mezclas.

\section{Referencias bibliográficas}

KoellreutTer, H.J. (1988-90). A. Estética do impreciso e do paradoxal. Notas de estudio suministradas por el Instituto de Estudios Españoles de la USP.

MACHADO, C. et al. (1984). Critérios para a divulgação da pesquisa científica. Uma ampliação da semiótica peirceana. Informe de pesquisa 4/84. Instituto de Economía Agrícola de São Paulo.

Santaella Braga, Maria Lúcia et al. (1978). Por um ensino melhor.

Treinamento de professores do ensino de $1 .^{\circ}$ grau por multimeios.

Cuaderno n. ${ }^{\circ}$ VIII. Mec/Prontel. 
- (1980). «Por uma classificação da linguagem escrita». En Produção de linguagem e ideologia. São Paulo: Cortez editora, 2. ${ }^{a}$ edição revista e ampliada, 1996.

- (1988). «For a classification of visual language». En Semiótica 70-1/2, 59-78. Berlim: Mouton de Gruyter. La versión de ese texto en portugués aparece en la revista FACE, volumen 2, número 1, 43-67. São Paulo: EDUC.

- (1992). A assinatura das coisas. Peirce e a literatura. Rio de Janeiro: Imago.

- (1995). A teoría geral dos signos. Semiose e autogeração. São Paulo: Ática. 